This journal is the official publication of Bangladesh Society of Physiologists (BSP)

Web URL: www.banglajol.info/index.php/JBSP

Abstracted /indexed in Index Copernicus, Director of Open Access Journal, HINARI Index Medicus for South East Asia Region, Google Scholar, 12OR, infobse index, Open J gate, Cite factor, Scientific indexing services

pISSN-1983-1213; e-ISSN-2219-7508

Article

Article information:

Received: $16^{\text {th }}$ January 2020

Accepted: $22^{\text {nd }}$ May 2021

DOI: https://doi.org/10.3329/jbsp.v16i1.54353

Corresponding author:

Dr. Miliva Mozaffor, Assistant Professor and

Laboratory consultant, Department of

Biochemistry, Medical College for Women \&

Hospital, Uttara, Dhaka- 1230. Email: miliva17

(a)yahoo.com

Cite this article:

Huda RM, Mozaffor M, Alam MA, Hosain MD

Acute ST-elevation myocardial infarction associated with metabolic syndrome and its angiographic outcome. J Bangladesh Soc Physiol $2021 ; 16(1) 49-56$

This article is open access licensed under CC BY NC SA which allows readers copy, distribute, display, and perform the work and make derivative works based on it only for noncommercial purposes.

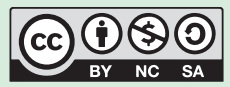

\section{Acute ST-Elevation Myocardial Infarction Associated with Metabolic Syndrome and Its Angiographic Outcome}

\author{
Reaz Mahmud Huda' ${ }^{1}$, Miliva Mozaffor ${ }^{2}$, Mohammad \\ Ashraful Alam ${ }^{1}$, Md. Delwar Hossain ${ }^{1}$ \\ 1. Department of Cardiology, National Institute of Cardiovascular Diseases \\ (NICVD), Dhaka-1207. \\ 2. Department of Biochemistry,Medical College for Women \& Hospital, Uttara, \\ Dhaka-1230.
}

\section{Abstract}

Background: Metabolic Syndrome is already one of the major public health problems around the world; it may be more grievous when associated with any cardiac emergency like myocardial infarction (MI). Objective: To evaluate the association of metabolic syndrome and its angiographic effects on patients with Acute ST-Elevation Myocardial Infarction (acute STEMI). Methods: This prospective observational study was done in the Department of Cardiology of the National Institute of Cardiovascular Diseases (NICVD), Dhaka, Bangladesh, between July and December of 2013. A total 233 patient were selected for data collection; of them 109 were in group I (acute STEMI patients with metabolic syndrome) and 124 in group II (acute STEMI patients without metabolic syndrome). Initial evaluation of the patients was done by history taking and clinical examination. Baseline investigations like ECG, CK(MB), lipid profile, fasting blood sugar, serum creatinine and echocardiography were done. Coronary angiogram (CAG) was done in the Cardiac Cath-Lab facility of the same hospital. Data was analyzed by using SPSS version 16.0. Comparison between groups was done by unpaired t-test, while categorical data was analyzed with Chi-square $\left(\chi^{2}\right)$ test. Results: In patients with metabolic syndrome (group I), most of them (68.9\%) had more than 2 metabolic components out of 4; the combinations were: high TG + low HDL (54.6\%), DM + high TG (46.9\%), raised $\mathrm{BP}+$ high TG (38.5\%), DM + low HDL (33.6\%), raised BP + 
low HDL (26.4\%) and raised BP and DM (24.3\%).ECG shows that the inferior wall acute myocardial infarction (MI) was $41.28 \%$ and $44.55 \%$ in group I and group II respectively, while anterior wall was involved $58.71 \%$ and $55.65 \%$ cases respectively, which was not statistically significant. Heart failure was significantly more in patients of group I than group II (46.79\% vs. $20.97 \% ;$ p $<0.001$ ). Echocardiography reveals that the left ventricular (LV) ejection fraction (EF) was much less in group I than that of group II ( $42.8 \pm 18.07 \%$ vs. $50.4 \pm 21.2 \%$; $\mathrm{p}<0.001)$. Among the patients who underwent coronary angiogram (CAG), the mean Friesinger score were $9.7 \pm 2.5$ in group I and 7.1 \pm 3.3 in group II $(\mathrm{p}<0.05)$; it indicated more chances of severe coronary artery disease and fatality in group I patients. Conclusion: Acute ST-elevation myocardial infarction patients with metabolic syndrome have much worse angiographic outcome and poor prognosis than those without metabolic syndrome.

Keywords: Myocardial infarction, metabolic syndrome, cardiovascular disease, angiographic outcome.

Introduction

$\mathbf{M}$ etabolic Syndrome is already one of the major public health problems of the 21 st century ${ }^{1}$. However, the diagnosis of metabolic syndrome is simple, mainly done by using clinical information and biochemical tests that are available in any health care system. The concept of the metabolic syndrome as a cluster of cardiovascular risk factors occurring in association with insulin resistance was brought to the wider scientific community in the American Diabetic Association (ADA) Scientific Sessions in 1988, through an informative lecture given by Reaven ${ }^{2}$. The frequent simultaneous presence of obesity, hyperlipidemia, diabetes mellitus and hypertension were first described in the late $60 \mathrm{~s}$, and subsequently highlighted in the late 70 s by many researchers who coined the term "metabolic syndrome" and described its association with atherosclerosis ${ }^{3,4}$. Today metabolic syndrome is a matter of immense public health concern for its atherosclerotic presentation. The syndrome may affect more than $50 \%$ of the elderly in the United States and even higher percentages in various ethnic groups around the world ${ }^{4}$. Metabolic Syndrome is a major public health problem; it may be grievous when associated with any cardiac emergency like myocardial infarction(MI), as studies based on populations at high risk for cardiovascular disease have shown a very high prevalence of metabolic syndrome ${ }^{4-6}$. Moreover, metabolic syndrome represents a cluster of several risk factors, each of which may be involved in this poor outcome of the acute MI patients 7,8 . There are several literatures available from western countries on impact of presence of metabolic syndrome on acute MI patients, which can be predicted by angiographic evidence ${ }^{8}$. However, there are only few reports available in the literature on angiographic outcomes of metabolic syndrome patients with Acute STElevation Myocardial Infarction (acute STEMI) in our country. Hence, in the present study, we tried to evaluate the angiographic impact of metabolic syndrome on patients with Acute STElevation Myocardial Infarction (acute STEMI). 
Methods

This prospective observational study was done in the Department of Cardiology of the National Institute of Cardiovascular Diseases (NICVD), Dhaka, Bangladesh, between July and December of2013. The study population were the patients with acute STEMI, with metabolic syndrome (group I) and without metabolic syndrome (group II), who were admitted into NICVD Hospital at that time. We adopted the Convenience Sampling technique. Our inclusion criteria for group I included patients having acute STEMI (the diagnosis of acute ST-Elevation Myocardial Infarction was done according to the "third universal definition of myocardial infarction' $)^{9}$ admitted into the hospital within 12 hours of onset of chest discomfort, who fulfilled the criteria of 'International Diabetic Federation (IDF) definition of metabolic syndrome' ${ }^{10}$ and received streptokinase therapy after admission. While group II included patients having acute STEMI patients admitted into the hospital within 12 hours of onset of chest discomfort, with no evidence of metabolic syndrome, and received streptokinase therapy as well. However, our exclusion criteria involved patients of acute STEMI patients who arrived $>12$ hours of onset of chest discomfort, with previous myocardial infarction (MI), or Percutaneous Coronary Intervention (PCI) or Coronary Artery Bypass Grafting (CABG), or having cardiomyopathy, congenital heart disease, or valvular heart disease, and with acute infections, neoplastic disease, chronic renal insufficiency and other severe chronic diseases.

Data collection was done after taking written informed consent from each patient or from his/ her legal guardian who fulfilled the criteria. Total 233 patient were selected for data collection; in group I, 109 and in group II, 124 patients were included. Initial evaluation of the patients done by history and clinical examination was recorded in the preformed data collection sheet. Demographic profile, pulse, blood pressure, body weight, waist circumference and ECG report at emergency room were recorded. Risk factors like history of hypertension, smoking, dyslipidemia, diabetes mellitus and obesity were also noted. Detailed drug history was taken. Those who were previously hypertensive and taking antihypertensive drugs were counted as hypertensive patients. For the rest the highest blood pressure value on the second and third day were also taken for the record. Baseline investigations like ECG (done by the Fukuda Denshi-FX-2111 EKG Machine, made in Japan), $\mathrm{CK}(\mathrm{MB})$, lipid profile, fasting blood sugar, serum creatinine and echocardiography (done by the GE Vivid S5 Ultrasound Machine, made in USA) were done. Serum levels of triglyceride and total cholesterol were measured by enzymatic method. High density lipoprotein (HDL) was measured by the direct method using elimination/catalase, while low density lipoprotein (LDL) cholesterol was derived using the 'Friedewald formula'. Blood glucose was measured by enzymatic method. All the blood samples were analyzed within 2 hours of collection. Coronary angiogram (CAG) was done in the Cardiac Cath-Lab facility of the same hospital. For the patients undergone coronary angiogram, their angiographic severity of coronary artery disease assessment was done by using 'Friesinger score'11. Data were analyzed by using SPSS (Statistical Package for Social Science) version 16.0. Comparison between groups was done by unpaired t-test, while categorical data was analyzed with Chi-square $\left(\chi^{2}\right)$ test.

\section{Results}

The mean age of the patients in group I and group II were $54.59 \pm 10.44$ and $53.24 \pm 9.40$ years respectively. However, the mean age difference was not statistically significant $(p>0.05)$ (Table I). Both group I and group II have almost similar sex distribution (male-67.80\% vs. $68.54 \%$; female-32.11\% vs. $31.45 \%$ ), without any statistical difference. The common risk factors for ischemic heart disease (IHD) at 
admission were shown in Figure 1. It was found that $34.86 \%$ of the patients in group I were hypertensive in contrast to $25.8 \%$ of those in group II. Diabetes mellitus was found $41.28 \%$ in group I and $14.51 \%$ in group II. Besides, $22.01 \%$ and $16.93 \%$ patients were dyslipidemic in group I and group II respectively. $51.37 \%$ of group I and $58.06 \%$ of group II were current smoker/had history of smoking. Family history of cardiovascular disease was present in 19.26\% and $16.12 \%$ in group I and group II respectively. All common risk factors were statistically nonsignificant $(p>0.05)$, except diabetes $(p=0.007)$. The mean waist circumference in male patients was $96 \pm 4.9 \mathrm{~cm}$ in group I and $84 \pm 5.6 \mathrm{~cm}$ in group II. In contrast, the mean of waist circumference in female patients was $84 \pm 3.5 \mathrm{~cm}$ in group I and $74 \pm 5.5 \mathrm{~cm}$ in group II. Differences of waist circumference in male and female were statistically significant between group I and group II $(\mathrm{p}<0.01)$ (Table II).

In patients with metabolic syndrome i.e. group I, most of them (68.9\%) had more than 2 metabolic components out of 4 ; the combinations were: high TG + low HDL (54.6\%), DM + high TG (46.9\%), raised BP + high TG (38.5\%), DM + low HDL (33.6\%), raised BP + low HDL (26.4\%) and raised BP and DM (24.3\%). (Figure 2). ECG shows that the inferior wall acute myocardial infarction (MI) was $41.28 \%$ in group I and $44.55 \%$ in group II, while anterior wall was involved in $58.71 \%$ in group I and $55.65 \%$ in group II; however, there was no statistical difference (Figure 2).

Table I : Distribution of the patients by age $(n=233)$

\begin{tabular}{|c|c|c|c|c|c|}
\hline \multirow[t]{2}{*}{ Age in years } & \multicolumn{2}{|c|}{ Group I } & \multicolumn{2}{|c|}{ Group II } & \multirow[t]{2}{*}{$P$ value } \\
\hline & $\mathrm{n}$ & $\%$ & $\mathrm{n}$ & $\%$ & \\
\hline $30-39$ & 14 & 12.84 & 14 & 11.24 & ${ }^{\mathrm{a}} 0.654^{\mathrm{NS}}$ \\
\hline $40-49$ & 26 & 23.85 & 36 & 29.03 & ${ }^{\mathrm{a}} 0.134^{\mathrm{NS}}$ \\
\hline $50-59$ & 29 & 26.60 & 31 & 25.0 & ${ }^{\mathrm{a}} 0.966^{\mathrm{NS}}$ \\
\hline $60-69$ & 32 & 29.35 & 35 & 28.22 & $\mathrm{a} 0.755^{\mathrm{NS}}$ \\
\hline$>69$ & 8 & 07.33 & 8 & 06.45 & ${ }^{\mathrm{a}} 0.553 \mathrm{NS}$ \\
\hline Total & 109 & 100.0 & 124 & 100.0 & \\
\hline Mean \pm SD & \multicolumn{2}{|c|}{$54.59 \pm 10.44$} & \multicolumn{2}{|c|}{$53.24 \pm 9.40$} & $\mathrm{~b}_{0.550} \mathrm{NS}$ \\
\hline
\end{tabular}

Group I: Patients with metabolic syndrome; Group II: Patients without metabolic syndrome; NS: Non-significant; a: $p$ value determined by $\chi^{2}$ test; $b$ : $p$ value determined by unpaired $t$-test.

Table II : Mean waist circumference ( $\mathrm{n}=233)$

\begin{tabular}{lccc}
\hline Waist circumference $(\mathrm{cm})$ & Group I & Group II & P value \\
\hline Male & $96 \pm 4.9$ & $84 \pm 5.6$ & $0.002^{* *}$ \\
Female & $84 \pm 3.5$ & $74 \pm 5.5$ & $0.003^{* *}$ \\
\hline
\end{tabular}

$* *=$ Significant at the level of $\mathrm{p}<0.01$; $\mathrm{p}$ value was determined by unpaired $\mathrm{t}$-test.

Group I: Patients with metabolic syndrome; Group II: Patients without metabolic syndrome 


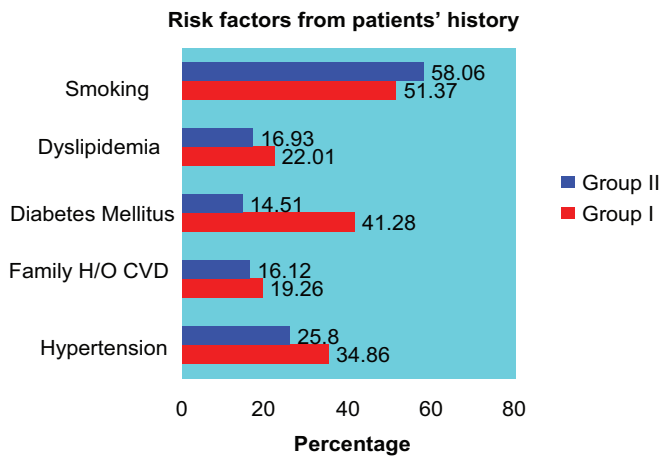

Figure 1. Distribution of common risk factors of Ischemic Heart Disease (IHD) ( $\mathrm{n}=233$ )

Heart failure (as defined by Hasdai et al. ${ }^{12}$ was significantly more in group I patients than those of group II (46.79\% vs. $20.97 \%$; $p<0.001)$. The difference in incidence of Killip class I and cardiogenic shock was not statistically significant between the groups; however, Killip class II (22.94\% vs. $09.68 \%$; $\mathrm{p}=0.005)$ and class III $(11.93 \%$ vs. $02.42 \% ; \mathrm{p}<0.001)$ heart failure were significantly more in group I (Table III). While measuring the Left Ventricular Ejection Fraction (LVEF), it was found that group I had statistically significant number of patients in the range of LVEF $26-40 \%$ ( $25.69 \%$ vs. $06.45 \%$; $p<0.001)$. The maximum $52.29 \%$ of patients in group I had LVEF in the range of $41-49 \%$ in comparison to $31.45 \%$ in group II $(p<0.05)$. Whereas, group II had maximum $60.48 \%$ of patients in LVEF range $\geq 50 \%$ in comparison to 18.35 of group I $(\mathrm{p}<0.001)$. Only $03.67 \%$ of the group I and $1.61 \%$ of the group II had EF in the range of

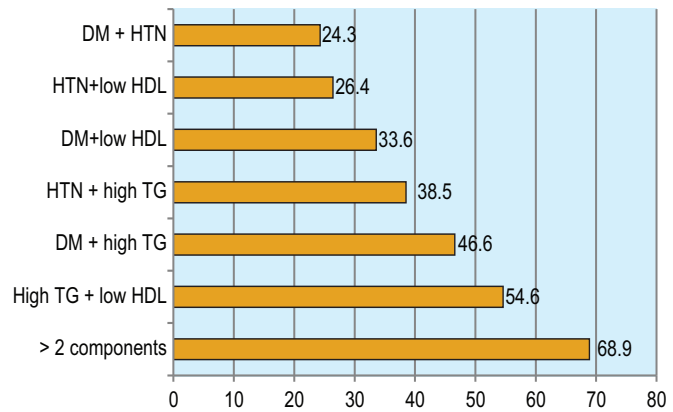

Figure 2. Distribution of metabolic components present during diagnosis of metabolic syndrome in group $\mathrm{I}(\mathrm{n}=109)$

$\leq 25 \%$ ( $\mathrm{p} 0.05$ ). The means of LVEF were $42.8 \pm 18.07 \%$ and $50.4 \pm 21.2 \%$ in group I and group II respectively, which was statistically significant $(p<0.001)$ (Table IV). A total of 112 patients underwent coronary angiogram $(\mathrm{CAG})$, 53 from group I and 59 from group II. Based on Friesinger score of those patients, score 1-4 was found $03.77 \%$ patients in group I and $22.03 \%$ patients in group II which was statistically significant $(\mathrm{p}<0.01)$. Friesinger score 5-10 was found $50.94 \%$ and $50.85 \%$ patients in group I and II respectively, which had no statistical difference, while score 11-15 was found in $45.29 \%$ and $27.12 \%$ patients in group I and II respectively, which was statistically significant $(\mathrm{p}<0.05)$. The mean Friesinger score were $9.7 \pm 2.5$ and $7.1 \pm 3.3$ in group I and II respectively, and the difference was ultimately statistically significant $(p<0.05)($ Table V).It indicated more chances of severe coronary artery disease and fatality in group I patients.

Table III : Incidence of heart failure $(\mathrm{n}=233)$

\begin{tabular}{lcccccc}
\hline Killip class & \multicolumn{2}{c}{ Group I $(\mathrm{n}=109)$} & & \multicolumn{2}{c}{ Group II $(\mathrm{n}=124)$} & P value \\
\cline { 2 - 3 } & $\mathrm{n}$ & $\%$ & & $\mathrm{n}$ & $\%$ & \\
\hline Heart failure (any class) & 51 & 46.79 & & 26 & 20.97 & $0.001^{* * *}$ \\
Killip class I & 4 & 3.67 & & 4 & 03.26 & $0.504^{\mathrm{NS}}$ \\
Killip class II & 25 & 22.94 & & 12 & 09.68 & $0.005^{* *}$ \\
Killip class III & 13 & 11.93 & & 3 & 02.42 & $0.001^{* * *}$ \\
Cardiogenic shock & 9 & 08.27 & 7 & 05.64 & $0.500^{\mathrm{NS}}$ \\
\hline
\end{tabular}

NS $=$ Non-significant $; *=$ Significant at the level of $\mathrm{p}<0.01 ; * * *=$ Significant at the level of $\mathrm{p}<0.001 ; \mathrm{p}$ value determined by $\div 2$ test. Group I: Patients with metabolic syndrome; Group II: Patients without metabolic syndrome

Volume 16 No. 1 June 2021: 49-56 
Table IV : Left Ventricular Ejection Fraction (LVEF) $(\mathrm{n}=233)$

\begin{tabular}{lcccccc}
\hline Left Ventricular Ejection Fraction & \multicolumn{2}{c}{ Group I } & & \multicolumn{2}{c}{ Group II } & P value \\
\cline { 2 - 3 }$(\mathrm{LVEF})(\%)$ & $\mathrm{n}$ & $\%$ & & $\mathrm{n}$ & $\%$ & \\
\hline$\leq 25$ & 4 & 03.67 & & 01.61 & ${ }^{\mathrm{a}} 0.211^{\mathrm{NS}}$ \\
$26-40$ & 28 & 25.69 & & 8 & 06.45 & ${ }^{\mathrm{a}} 0.001^{* *}$ \\
$41-49$ & 57 & 52.29 & & 39 & 31.45 & ${ }^{\mathrm{a}} 0.048^{*}$ \\
${ }^{3} 50$ & 20 & 18.35 & & 75 & 60.48 & ${ }^{\mathrm{a}} 0.001^{* *}$ \\
Total & 109 & 100.0 & & 124 & 100.0 & \\
Mean \pm SD & $42.8 \pm 18.07$ & & $50.4 \pm 21.2$ & ${ }^{\mathrm{b}} 0.001^{* *}$ \\
\hline
\end{tabular}

$\mathrm{NS}=$ Non-significant; $*=$ Significant at the level of $\mathrm{p}<0.05 ; * *=$ Significant at the level of $\mathrm{p}<0.01 ; \mathrm{a}=\mathrm{p}$ value determined by $\chi^{2}$ test $; \mathrm{b}=\mathrm{p}$ value determined by unpaired $\mathrm{t}$-test.

Group I: Patients with metabolic syndrome; Group II: Patients without metabolic syndrome

Table V: Friesinger score of the study patients who underwent coronary angiogram $(\mathrm{n}=112)$

\begin{tabular}{|c|c|c|c|c|c|}
\hline \multirow[t]{2}{*}{ Friesinger score } & \multicolumn{2}{|c|}{ Group $\mathrm{I}(\mathrm{n}=53)$} & \multicolumn{2}{|c|}{ Group II(n=59) } & \multirow{2}{*}{$\begin{array}{c}\mathrm{P} \\
\text { value }\end{array}$} \\
\hline & $\mathrm{N}$ & $\%$ & $\mathrm{n}$ & $\%$ & \\
\hline 0 & 0 & 0.0 & 0 & 0.0 & \\
\hline $1-4$ & 2 & 03.77 & 13 & 22.03 & a $0.001 * *$ \\
\hline $5-10$ & 27 & 50.94 & 30 & 50.85 & a $0.091^{\mathrm{ns}}$ \\
\hline $11-15$ & 24 & 45.29 & 16 & 27.12 & a $0.032 *$ \\
\hline Mean \pm SD & 9.7 & \pm 2.5 & 7.1 & \pm 3.3 & b $0.036^{*}$ \\
\hline Range & \multicolumn{2}{|c|}{$(4-14)$} & \multicolumn{2}{|c|}{$(1-14)$} & \\
\hline
\end{tabular}

NS $=$ Non-significant; $* *=$ Significant at the level of $\mathrm{p}<0.01 ; *=$ Significant at the level of $\mathrm{p}<0.05 ; \mathrm{a}$ : $\mathrm{p}$ value reached from $\chi^{2}$ test; $\mathrm{b}$ : $\mathrm{p}$ value reached from Unpaired $\mathrm{t}$-test.

Group I: Patients with metabolic syndrome; Group II: Patients without metabolic syndrome

\section{Discussion}

Metabolic syndrome is associated with an increased risk of cardiovascular disease ${ }^{13}$. Of all the acute STEMI patients with discomfort in the chest $<12$ hours duration admitted in Coronary Care Unit (CCU) of NICVD. Dhaka, Bangladesh, from July to December of 2013, a total of 233 were included in this study.

In this study the age group of metabolic syndrome patients is consistent with Zaher et al ${ }^{14}$ observed in Bangladeshi population. Male female ratio was 2.15:1. in two groups did not agree to Zaher et al. ${ }^{14}$, where the sex ratios were 8.04:1.Among the components of metabolic syndrome, hyperglycemia was found to have the strongest association for development of heart failure in our study, followed by low HDL and high triglyceride. However, raised BP has much less significant association here. Hyperglycemia was also found to be the strongest associated factor for development of heart failure in the study conducted by Zeller et al. ${ }^{15}$, followed by low HDL and high TG respectively. Triglycerides in blood became an associated factor for heart failure which may be explained by the genetic abnormalities for TG regulation that was found

Volume 16 No. 1 June 2021: 49-56 
in the Asian Indian population as described by Deedwania \& Singh $^{16}$ and Lee et al. ${ }^{17}$ in their studies. Several studies have shown that high prevalence of small dense low density lipoprotein (LDL), together with the increased triglyceride (TG) and decreased HDL levels, forms the "atherogenic lipoprotein phenotype", a potent risk factor for coronary heart disease (CHD), are prevalent in South Asian and may partly explain the excess CAD risk in this population ${ }^{16}$. The lipid profile of our study is also consistent with the general South Asian profile. The study done by Bhopal et al. ${ }^{18}$ revealed similar findings in South Asians. Even in a study conducted on European population by Zeller et al. ${ }^{15}$ found that $80 \%$ of the acute MI patients with metabolic syndrome had low HDL and 57\% had high TG in comparison to non-metabolic syndrome patients (22\% and $14 \%$ respectively).

We found much more heart failure in patients with metabolic syndrome than the other group. It was also evident in previous study that metabolic syndrome itself is an independent predictor of heart failure in men $>50$ years, as studied by Ingelsson, Arnlov \& Sundstrom ${ }^{19}$, in large population of 2314 with a long term follow up of 20 years. Heart failure group had more patients in the range of $11-15$ (55\% vs. $45 \%)$.da Luz et al. ${ }^{20}$ observed Friesinger score 0 in $19.0 \%$, score 1 - 4 was $17.9 \%$, score $5-10$ was $36.1 \%$ and score $11-15$ was $27.0 \%$ in suspected cases of coronary artery disease. Bampi et al. ${ }^{21}$ found Friesinger score 0 in $37.0 \%$, score $1-4$ was $07.0 \%$, score $5-10$ was $32.0 \%$ and score $11-15$ was $24.0 \%$ in their study patients. The findings of our study are more or less similar to that of da Luz et al. ${ }^{20}$ and Bampi et al. ${ }^{21}$.

The limitations of the study include smaller sample size as the study subjects were selected purposively, limited follow up of the patients due to time constraint, and unavailability of coronary angiogram to all the patients due to their financial problem. Hence, it is difficult to generalize our findings to the reference population.

Volume 16 No. 1 June 2021: 49-56

\section{Conclusion}

Our data showed that the acute ST-elevation myocardial infarction patients with metabolic syndrome have much worse angiographic outcome and poor prognosis than those without metabolic syndrome. However, we recommend further studies in the same ethnic population with lager samples and longer duration, ensuring availability of better emergency treatment facility and high technical back-up.

Ethical issue: The study was approved by the Ethics Review Committee of Bangladesh College of Physicians and Surgeons (BCPS), Dhaka, Bangladesh.

Conflict of interest: There is no conflict of interest relevant to this paper to disclose.

\section{References}

1. Zimmet P, Magliano D, Matsuzawa Y, Alberti G, Shaw J.The metabolic syndrome: a global public health problem and a new definition.J Atheroscler Thromb. 2005;12(6):295-300

2. Reaven GM. Banting Lecture 1988. Role of insulin resistance in human disease. Diabetes. 1988;37(12): 1595-607.

3. Alexander CM, Landsman PB, Teutsch SM, Haffner SM. NCEP-defined metabolic syndrome, diabetes and prevalence of coronary heart disease among NHANES III participants age 50 years and older. Diabetes. 2003;52(5):1210-4.

4. Cameron AJ, Shaw JE, Zimmet PZ. The metabolic syndrome: prevalence in worldwide populations. Endocrinol Metab Clin North Am. 2004;33(2):35175.

5. Miranda PJ, DeFronzo RA, Califf RM, Guyton JR. Metabolic syndrome: definition, pathophysiology, and mechanisms. Am Heart J. 2005;149(1):33-45.

6. Ford ES. The metabolic syndrome and mortality from cardiovascular disease and all-causes: findings from the National Health and Nutrition Examination Survey II Mortality Study.Atherosclerosis. 2004;173(2):30914.

7. Hasdai D, Califf RM, Thompson TD,Hochman JS,Ohman EM,Pfisterer MP,Bates ER, Vahanian A,Armstrong PW,Criger DA,Topol EJ,Homes DR. Predictors of cardiogenic shock after thrombolytic 
therapy for acute myocardial infarction. J Am Coll Cardiol. 2000;35(1):136-43

8. Solymoss BC, Bourassa MG, Campeau L, Lespérance J Lévesque S, Varga S. Effect of increasing metabolicsyndrome score on atherosclerotic risk profile and coronary artery disease angiographic severity. Am J Cardiol. 2004;93(2):159-64.

9. Thygesen K, Alpert JS, Jaffe AS, , Simoons ML, Chaitman BR, White HD. Third universal definition of myocardial infarction. Eur Heart J. 2012;33(20):2551-67.

10. International Diabetes Federation (IDF). The IDF consensus worldwide definition of the metabolic syndrome. Brussels, Belgium: 2006.[internet] [cited July 14, 2013] Retrieved from: https://www.idf.org/elibrary/consensus-statements/60-idfconsensusworldwide-definitionof-the-metabolic-syndrome.html.

11. Ringqvist I, Fisher LD, Mock M, Davis KB, Wedel H, Chaitman BR, Passamoni E, Rusell Jr RO, Alderman EL, Kouchoukas NT, Kaiser GC,Ryan TJ,Killip T,Fray D. Prognostic value of angiographic indices of coronary artery disease from the Coronary Artery Surgery Study (CASS). J Clin Invest. 1983;71(6):185466.

12. Hasdai D, Topol EJ, Califf RM, Berger PB, Holmes DR Jr. Cardiogenic shock complicating acute coronary syndromes. Lancet. 2000;356(9231):749-56.

13. Grundy SM. Metabolic syndrome: connecting and reconciling cardiovascular and diabetes worlds. J Am Coll Cardiol. 2006;47(6):1093-100.

14. Zaher A, Majumder AAS, Mohibullah AKM. Homocysteine as a risk factor for coronary artery disease in Bangladeshi population. Bangladesh Heart J. $2003 ; 18(1): 3-8$.
15. Zeller M, Steg PG, Ravisy J,Laurent Y,Manificat LJ,Hullier L,Beer JC,Oudot A, Rioufol,J, Makki H, Farnir M, Rochette L, Verges B, Cottin Y. Prevalence and impact of metabolic syndrome on hospital outcomes in acute myocardial infarction. Arch Intern Med. 2005;165(10):1192-8.

16. Deedwania P, Singh V. Coronary artery disease in South Asians: evolving strategies for treatment and prevention. Indian Heart J. 2005;57(6):617-31.

17. Lee MG, Jeong MH, Ahn Y, Chae SC, Hur SH, Hong TJ, Kim YJ, Seong IW, Chae JK, Rhew JY, Chae IH, Cho MC, Bae JH, Rha SW, Kim CJ, Choi D, Jang YS, Yoon J, Chung WS, Cho JG, Seung KB, Park SJ. Impact of the metabolic syndrome on the clinical outcome of patients with acute ST-elevation myocardial infarction. J Korean Med Sci. 2010;25(10):1456-61.

18. Bhopal R, Unwin N, White M, Yallop J Walker L, Alberti K G, Harland J, Patel S, Ahmad N, Turner C, Watson B, Kaur D, Kulkarni A, Laker M, Tavridou A. Heterogeneity of coronary heart disease risk factors in Indian, Pakistani, Bangladeshi, and European origin populations: cross sectional study. BMJ. 1999;319(7204):215-20.

19. Ingelsson E, Arnlov J, Lind L, Sundstrom J. Metabolic syndrome and risk for heart failure in middle-aged men. Heart. 2006;92(10):1409-13.

20. da Luz PL, Favarato D, Faria-Neto JR Jr, Lemos PA, Chagas ACP. High ratio of triglycerides to HDLcholesterol ratio predicts extensive coronary disease. Clinics (Sau Paulo Brazil). 2008;63(4):427-32.

21. Bampi ABA, Rochitte CE, Favarato D, Lemos PA, da Luz PL. Comparison of non-invasive methods for the detection of coronary atherosclerosis. Clinics (Sau Paulo). 2009;64(7):675-82. 